\title{
EFFECTS OF FLY ASH ON MECHANICAL PROPERTIES OF CONCRETE
}

\author{
Masoud Zabihi-Samani a, *, Seyed Payam Mokhtari ${ }^{\text {b }}$, Farzaneh Raji ${ }^{\text {c }}$ \\ a* Department of Civil Engineering, Parand Branch, Islamic Azad University, Parand, Iran, e-mail: zabihi@ piau.ac.ir \\ ${ }^{\mathrm{b}}$ Young Researchers and Elite Club, Parand Branch, Islamic Azad University, Parand, Iran. \\ ${ }^{c}$ Department of Civil and Environmental Engineering, Florida International University, Miami, USA.
}

Received: 07.08.2018 / Accepted: 04.09.2018/ Revised: 26.11.2018 / Available online: 15.12.2018

DOI: $10.2478 /$ jaes-2018-0016

KEY WORDS: Fly ash, Transport properties, High temperature, Fracture toughness, Compressive strength.

\begin{abstract}
:
Cement is a common and widespread building material over the world. Similarly, carbon dioxide emissions have been significantly increased due to cement production. Alternative low-carbon binders rather than cement have been progressively sought in recent years. Fly ash was found as an available option, since it is being largely disposed annually as a waste material. In this research several studies have been reviewed and recent applications of fly ash on concrete specification, including strength and fracture toughness of green concrete have been perused. Furthermore, transport properties of high volume fly ash after exposure to high temperature and influence of curing temperature on strength development of fly ash-recycled concrete aggregate blends have been investigated. The investigated test results showed that the properties of composites incorporating fly ash depend on the age of the concrete. Test results also revealed that transport properties of concrete increased notably after exposure to $400 \mathrm{c}^{\circ}$ and the results achieved on fly ash-recycled concrete aggregate led to the conclusion that $15 \%$ FA is the optimum blend for road stabilization applications.
\end{abstract}

\section{INTRODUCTION}

Construction activities use huge amount of cement on a world scale and this activity results with $\mathrm{CO}_{2}$ emission to atmosphere which is considered one of the large environmental problems (Mo et al. 2015). The structures made of green concrete are environmentally sustainable and are constructed in such a way that the total impact on the environment during their full life cycle, including service life, is reduced to minimum. Cement substitution is important for sustainable construction because the production of cement not only uses a considerable amount of energy, but also emits a substantial amount of $\mathrm{CO}_{2}$ and other greenhouse gases (Mehta 2002; Zabihi-Samani et al. 2018).

Therefore, a permanent and environmentally sustainable material is extremely needed to reduce the Portland cement fabrication as one of the large contributor to emission. To achieve more green-world friendly concrete, by-product or waste material should be utilized rather than Portland cement. One of the most worldwide available by-product material is fly ash (FA), which is known as by-product from the industrial processes. Since FA is accepted as a secondary product of thermal electrical power plants due to the combustion of powdered coal in the coal-firing furnaces, there are million tons of industrial waste produced annually all around the world.

Up to date -750 million tons of the FA is generated each year in the world (Blissett and Rowson 2012; Ghanooni-Bagha et al. 2017). In the future, it should be expected to increase this quality to 2100 million tons in 2031-32(Amini and ZabihiSamani 2014; Hemalatha and Ramaswamy 2017). In general, researchers used up to $30 \% \mathrm{FA}$ in concrete as cement substitution, however larger amount of FA has been permitted to be substituted by modern standard, i.e. 55\% FA.

FA can substitute $50-70 \%$ cement in high volume FA concrete (Karahan 2017; Zabihi-Samani and Ghanooni-Bagha 2018a). Concrete incorporating FA must meet the requirements for strength and durability and its components should be obtained, produced and used in an environmentally friendly manner (Jayapalan et al. 2013; Zabihi-Samani and Amini 2015).

Nowadays, FA is a common additive, which is being widely used in many research purposes and also construction, mining

\footnotetext{
* Corresponding author: Masoud ZABIHI-SAMANI, E-mail: zabihi@ piau.ac.ir
} 
and terrain management, therefore the FA is a subject of exhaustive research.

\section{RESEARCH REVIEW}

In this paper to investigate the effects of FA as a useful additive, several recent and major studies have been reviewed. The summary can be expressed as follows:

\subsection{Study A}

Grzogorz Ludwik Golewski has studied the effect of coal fly ash (CFA) on the Improvement of fracture toughness and compressive strength of green concrete (Golewski 2017).

\subsubsection{Materials and research methodology:}

In this research, only two compositions of concrete mixture, with varying percentage of CFA additive, were planned in all experiments. All tests were carried out for green concretes modified with the CFA additive in the amount of $20 \%$ (CFA20 ) and $30 \%$ (CFA-30) of weight of cement. The results of experiments were compared to the values achieved for the reference concrete. Figure 1 displays the test setup equipment.

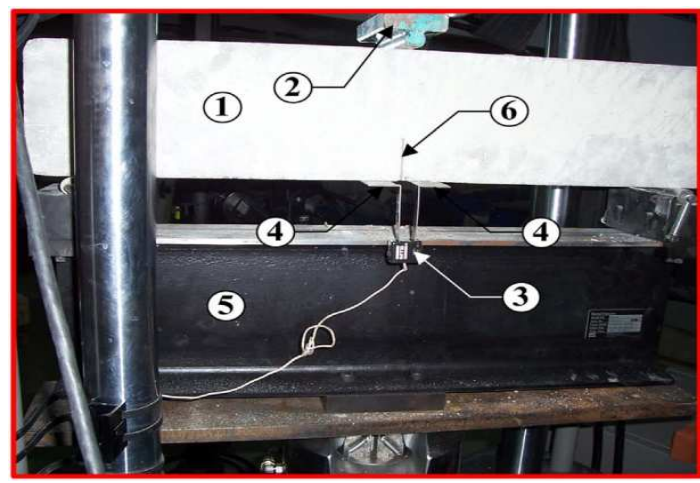

Figure 1. Laboratory test setup apparatus: 1 - specimen, 2 system applying force onto the specimen, 3 - axial clip gage extensometer, 4 - clamping test grips, 5 - supporting system, 6 - initial crack.

2.1.2. Compressive strength results: A noticeable decrease of compressive strength in concretes was analyzed at an early age, i.e. after 3 days and 7 days by CFA additive. According to Figure 2 the value of $f_{\mathrm{cm}}$ in CFA - 00, was higher by almost 8 and exactly by $10 \mathrm{Mpa}$ in comparison to CFA-20 and CFA-30, respectively, after 72 hours of curing. Generally, concrete with a larger amount of CFA was distinguished by the lowest strength in the period up to 3 months. After a half year of curing, the value of $\mathrm{f}_{\mathrm{cm}}$ for this composite was higher compared to concrete without the additives. After a year, the strength of CFA-30 was 4 Mpa higher compared to CFA-00, and lower by the same value, in comparison to CFA-20 (Golewski 2017).

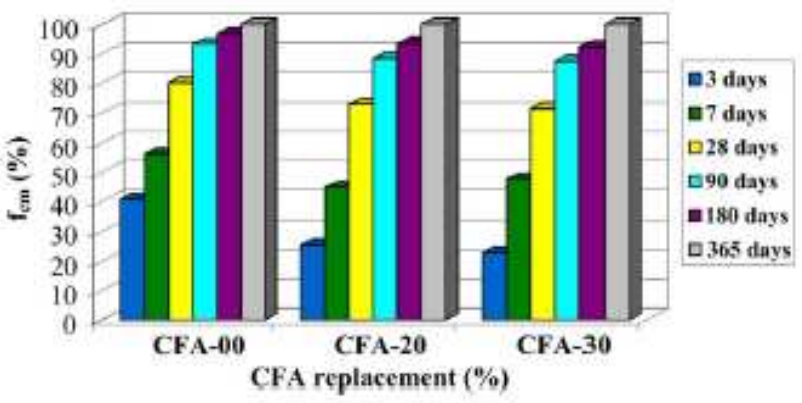

Figure 2. Relative changes of compressive strength over time

2.1.3. Fracture toughness results: The results of fracture toughness $\left(\boldsymbol{K}_{\mathcal{F}}\right)$ tests of concretes are indicated in Figure 3, for particular periods of curing. Values of fracture toughness, in the inceptive stages of curing of concretes were closely similar to the results of strength tests. This was clearly noticeable in composite with CFA additive. After 3 days, fracture toughness was $32 \%$ and $50 \%$ lower for CFA-20 and CFA-30, respectively, compared to the value achieved for CFA-00. In the following time periods for mature concretes a remarkable increase of fracture toughness took place in concrete with the $20 \% \mathrm{CFA}$ additive, for which values of $\boldsymbol{K}_{l \varepsilon}^{S}$ clearly exceeded the results achieved for two other materials.

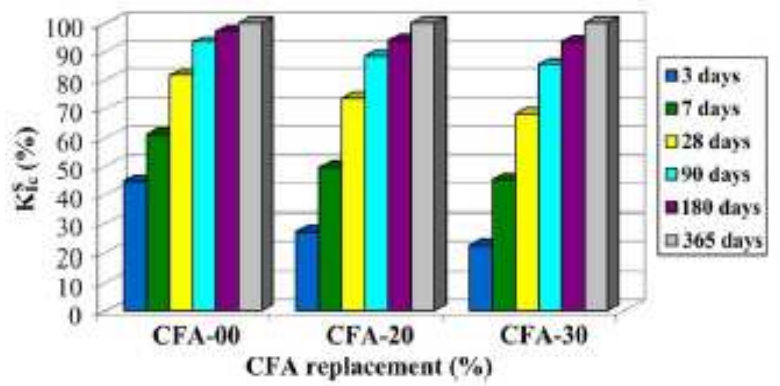

Figure 3. Relative changes of fracture toughness over time

\subsection{Study B}

Arul Arulrajah et al. have investigated the influence of class F fly ash and curing temperature on strength development of FA - recycled concrete aggregate blends(Arulrajah et al. 2016).

2.2.1. Materials and methods: In this research, recycled concrete aggregate (RCA) with a maximum size of $20 \mathrm{~mm}$ was achieved from a recycling facility in Melbourne, Australia. Black coal FA was collected from a power plant in the state of Queensland, Australia. In this study RCA with FA blends were investigated with contents of 5\%,10\%,15\%,20\%, 25\% and $30 \%$. Figure 4 indicates the chemical composition of fly ash, obtained from x-ray Fluorescence analysis. 


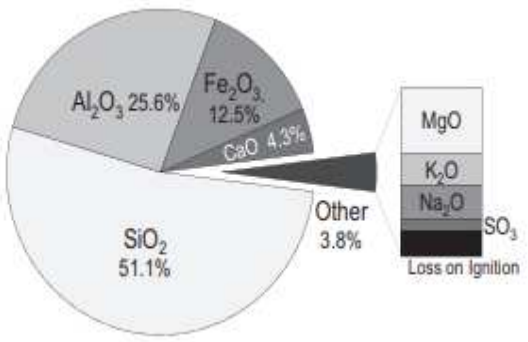

Figure 4. Chemical composition of FA from X-ray Fluorescence analysis

2.2.2. Results and discussion: Figure 5 indicates the unconfined compressive strength results of the RCA+FA blends. The rate of activation and strength of the blends were both obviously increased due to temperature curing. RCA with $15 \%$ FA was found to be the optimum blend for both roomtemperature and $40 \mathrm{c}^{\circ}$ curing condition. By increasing the FA amount more than $15 \%$ content, the unconfined compressive strength of the RCA+FA blend reduces till $25 \%$.

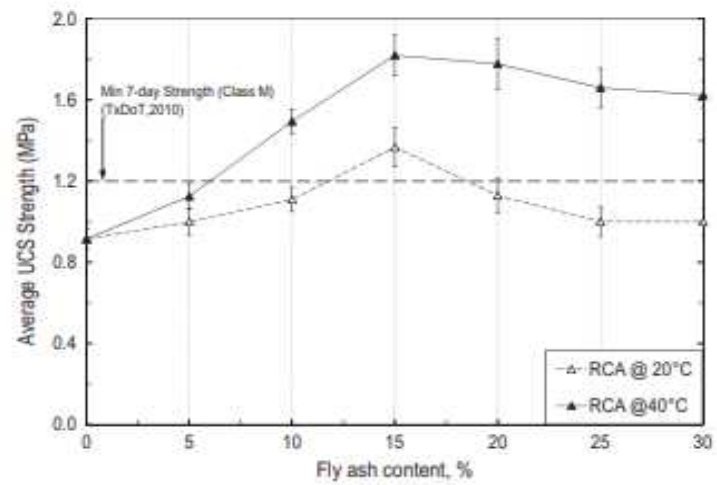

Figure 5. Strength development of FA stabilized RCA after 7 days of curing

Figure 6 presents the SEM analysis of $10 \%, 20 \%$ and 30\% FA stabilized RCA for 7 days cured specimens. It is obvious from the Figures that porosity of specimens has decreased remarkably by increasing the FA content. The Figure also indicates that the higher amount of FA additive does not necessarily result in the higher bands between the RCA aggregates because the number of unreacted FA particles increases (Arulrajah et al. 2016). Despite the fact that the reaction of the FA particles is accelerated by temperature curing, increasing the FA content will end in accumulation of unreacted FA particles. Mass of unreacted FA particles decreases the inter-particular aggregate interactions and consequently reduces the overall strength of the soil matrix.
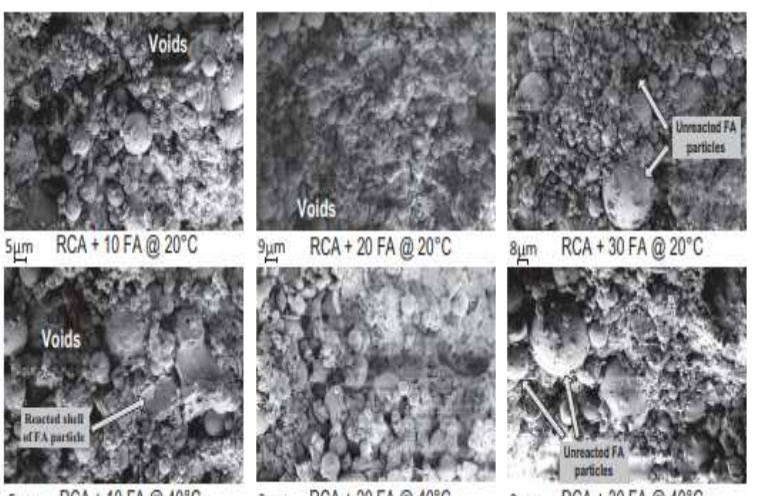

mim $R C A+20 F A @ 20^{\circ} \mathrm{C}$
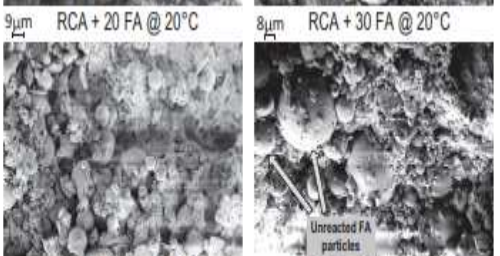

ium $\mathrm{RCA}+20 \mathrm{FA} @ 40^{\circ} \mathrm{C}$

8um RCA+30FA@40 $\mathrm{C}$

Figure 6. SEM Figure of RCA stabilized with FA at $20 c^{\text {a }}$ temperature and $40 \mathrm{c}^{\circ}$

\subsection{Study C}

Grzegorz Ludwik Golewski has investigated Green concrete composite incorporating FA in terms of high strength and fracture toughness (Golewski 2018).

2.3.1 Materials and methods: Binder of this investigation was composed of both ordinary Portland cement (OPC) and FA. Pit sand between sizes $0-2 \mathrm{~mm}$ and natural gravel of sizes between 2.0 and $8.0 \mathrm{~mm}$ were used as fine aggregate and coarse aggregate respectively. The plasticizer was used in an amount of $0.6 \%$ of mass of the binder. By using a compression machine (Walter+Baiag) with a maximum load of $3000 \mathrm{KN}$ the uniaxial compression strengths were tested and the testing of Mode 1 fracture toughness was performed according with the draft guidelines of RILEM recommendations (Brandt 1990), as shown in Figure 7.

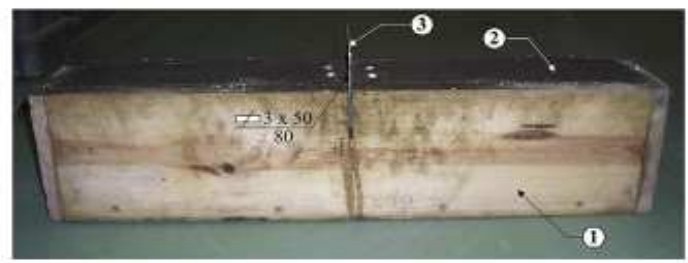

Figure 7. Specimen for mode 1 fracture tests during preparation: 1 - wooden form, 2 - concrete beam, 3 - steel plate

2.3.2. Compressive strength results: The results from compressive strength $\left(\mathrm{f}_{\mathrm{cm}}\right)$ tests of concrete, for particular periods of curing, are indicated in table 1, while Figure 8 presents relationships $\mathrm{f}_{\mathrm{cm}}$, as a function of the age of concretes. As it is evident, the compressive strength of specimens incorporating FA additive decreased noticeably at an early age, however, $\mathrm{f}_{\mathrm{cm}}$ increased with age in all the concrete specimens. According to (Golewski and Sadowski 2012), in which a more detailed analysis of changes of strength parameters in concretes with the FA additive at an early age is presented, clear disproportions in the obtained results occur within 14 days of curing. As summarized in table 1, 30\% FA concrete was characterized by the lowest compressive strength in the first 
three months period. After a half year of curing, value of $\mathrm{f}_{\mathrm{cm}}$ for this composite was higher compared to concrete without the additives, however, still lower in comparison to FA-20 (Golewski and Sadowski 2012).

2.3.3. Fracture toughness results: The results from fracture toughness $\left(K_{i C}^{\xi}\right)$ of concretes, for particular periods of curing, are shown in table 2. Furthermore, Figure 9 presents relationships $\mathbb{K}_{l c}^{\mathrm{S}}$, as a function of the age of concretes. Similar to the results obtained from compressive strength, values of $\mathbb{E}_{T C}^{9}$ were also very low at an early age. In subsequent time periods, for mature concretes, a substantial increase of fracture toughness happened in concrete with $20 \%$ FA additive. Due to accumulation of larger amount of micro-filler in concrete, FA30 experienced its lowest value of $\boldsymbol{K}_{\boldsymbol{L}}^{5} \mathrm{i}$ in the first 3 months. However, after 180 and 365 days, the highest fracture toughness belonged to FA-20 and FA-30.

Table 1. Compressive strengths results

\begin{tabular}{lllllll}
\hline Concrete & Age (days) & $\bar{f}_{\mathrm{Cm}}(\mathrm{MPa})$ & $\delta$ (MPa) & $\nu(\%)$ & $\begin{array}{l}f_{\mathrm{O}} \max . \\
(\mathrm{MPa})\end{array}$ & $\begin{array}{l}f_{\mathrm{C}, \min } \\
(\mathrm{MPa})\end{array}$ \\
\hline CFA-00 & 3 & 24.23 & 2.60 & 10.73 & 26.86 & 21.11 \\
& 7 & 33.18 & 2.57 & 7.74 & 35.42 & 30.71 \\
& 28 & 47.51 & 2.55 & 4.58 & 49.24 & 45.97 \\
& 90 & 55.13 & 2.51 & 4.55 & 57.02 & 53.18 \\
& 180 & 57.22 & 2.48 & 4.33 & 59.64 & 55.34 \\
& 365 & 59.25 & 2.46 & 4.15 & 61.43 & 57.79 \\
CFA-20 & 3 & 16.95 & 3.05 & 17.99 & 19.62 & 13.53 \\
& 7 & 30.12 & 3.03 & 10.06 & 26.84 & 33.15 \\
& 28 & 48.96 & 3.02 & 6.17 & 50.25 & 46.89 \\
& 90 & 59.35 & 2.80 & 4.72 & 61.21 & 58.65 \\
& 180 & 62.81 & 2.52 & 4.01 & 64.04 & 60.68 \\
CFA-30 30 & 365 & 67.29 & 2.35 & 3.49 & 69.32 & 66.13 \\
& 7 & 14.23 & 3.59 & 25.23 & 16.95 & 11.66 \\
& 28 & 30.06 & 3.57 & 11.88 & 32.28 & 27.84 \\
& 90 & 45.10 & 3.55 & 7.87 & 47.01 & 42.93 \\
& 180 & 58.11 & 3.10 & 5.63 & 56.72 & 53.49 \\
& 365 & 63.27 & 2.86 & 4.86 & 60.23 & 57.12 \\
& & 2.50 & 3.95 & 65.31 & 62.09 \\
\hline
\end{tabular}

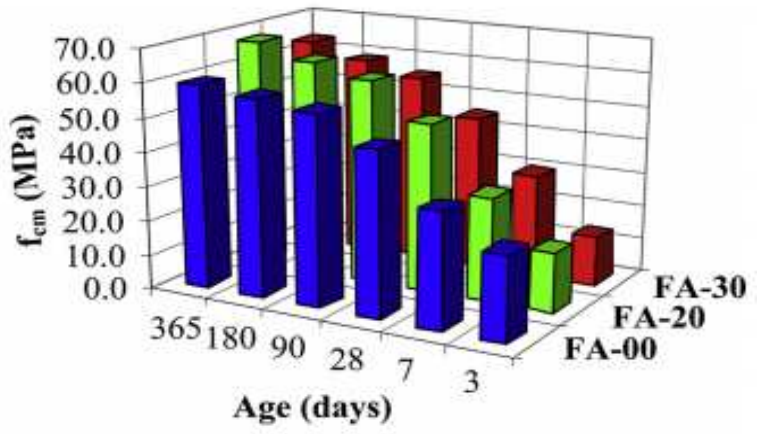

Figure 8. Effect of the FA content on the compressive strengths

Table 2. Fracture toughness results

\begin{tabular}{lllllll}
\hline Concrete & Age (days) & $\begin{array}{l}K_{\mathrm{lc}}^{\mathrm{S}} \\
(\mathrm{MN} / \\
\left.\mathrm{m}^{3 / 2}\right)\end{array}$ & $\begin{array}{l}\delta(\mathrm{MN} / \\
\left.\mathrm{m}^{3 / 2}\right)\end{array}$ & $\nu(\%)$ & $\begin{array}{l}K_{\mathrm{lc}} \mathrm{s}, \max . \\
\left(\mathrm{MN} / \mathrm{m}^{3 / 2}\right)\end{array}$ & $\begin{array}{l}K_{\mathrm{lc}} \mathrm{s}, \min . \\
\left(\mathrm{MN} / \mathrm{m}^{3 / 2}\right)\end{array}$ \\
\hline CFA-00 & 3 & 0.58 & 0.08 & 13.79 & 0.92 & 0.36 \\
& 7 & 0.79 & 0.09 & 11.39 & 1.14 & 0.57 \\
& 28 & 1.06 & 0.10 & 9.43 & 1.30 & 0.91 \\
& 90 & 1.21 & 0.08 & 6.61 & 1.49 & 1.02 \\
& 180 & 1.26 & 0.06 & 4.76 & 1.53 & 1.04 \\
& 365 & 1.30 & 0.05 & 3.85 & 1.51 & 1.10 \\
CFA-20 & 3 & 0.40 & 0.09 & 22.50 & 0.95 & 0.19 \\
& 7 & 0.73 & 0.09 & 12.33 & 1.02 & 0.60 \\
& 28 & 1.09 & 0.11 & 10.09 & 1.39 & 0.97 \\
& 90 & 1.31 & 0.10 & 7.63 & 1.52 & 0.99 \\
& 180 & 1.39 & 0.07 & 5.04 & 1.58 & 1.01 \\
& 365 & 1.48 & 0.06 & 4.05 & 1.62 & 1.07 \\
& 3 & 0.30 & 0.08 & 26.67 & 1.02 & 0.16 \\
& 7 & 0.62 & 0.08 & 12.90 & 1.22 & 0.36 \\
& 28 & 0.93 & 0.10 & 10.75 & 1.28 & 0.61 \\
& 90 & 1.17 & 0.09 & 7.69 & 1.43 & 0.98 \\
& 180 & 1.28 & 0.08 & 6.25 & 1.50 & 1.00 \\
& 365 & 1.37 & 0.07 & 5.11 & 1.61 & 1.01 \\
\hline
\end{tabular}

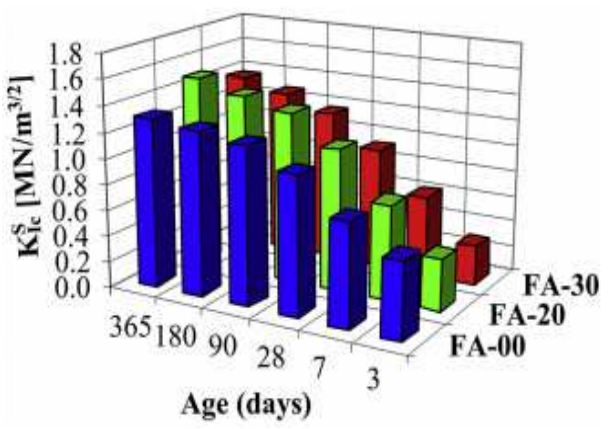

Figure 9. Effect of the FA content on the fracture toughness

\subsection{Study D}

Okan Karahan has investigated the effect of high volume fly ash on transport properties of concrete exposed to high temperature (Karahan 2017).

2.4.1. Materials and tests: In this research, natural fine and coarse aggregate were used in the experiments and Portland cement (PC) and also class F fly ash were used in the production of the concrete mixture. Experimental tests include one control concrete made without any FA and four concretes with $30 \%, 50 \%, 70 \%$ and $90 \%$ cement replacement by FA. Absorption, porosity and rapid chloride permeability tests were carried out to determine transport properties and additionally compressive strength test also was carried out. The RCPT setup is shown in Figure 10.

2.4.2. Absorption results: Results and the average of measurement of water absorption of the concretes exposed to high temperature are indicated in Figure 11. It is known that concrete with water absorption value less than 5\% was recognized as a high quality concrete (Kosmatka et al. 2002). As it is shown in Figure 11, the water absorption of concrete incorporating FA ranged from 4.4-7.3\%, 4.5-7.0\%, 5.7-8.1\% to $7.4-9.9 \%$ at the $20^{\circ} \mathrm{c}, 400^{\circ} \mathrm{c}, 600^{\circ} \mathrm{c}$ and $800^{\circ} \mathrm{c}$, respectively. Concretes containing 0\%, 30\%, 50\%, 70\% FA resulted in less than $5 \%$ water absorption at the $20^{\circ} \mathrm{c}$. Similarly, the water absorption results of less than 5\% were achieved for the concretes containing $0 \%, 30 \%$ fly ash at the $400^{\circ} \mathrm{c}$. According to these results, increase in high temperature up to $800^{\circ} \mathrm{c}$ leads in an increase in absorption value for all FA concretes. 
2.4.3. Porosity results: Figure 12 illustrates the results of porosity tests obtained from concretes incorporating high volume fly ash exposed to 400, 600 and $800^{\circ} \mathrm{c}$ high temperature. Figure 12 indicates that the porosity values of concretes incorporating high volume FA ranged from $10.0 \%$ to $15.6 \%$ at $20^{\circ} \mathrm{c}$. The highest value of porosity belonged to concrete containing $90 \%$ FA at all temperatures. And the lowest value of porosity belonged to concrete containing $30 \%$ FA.

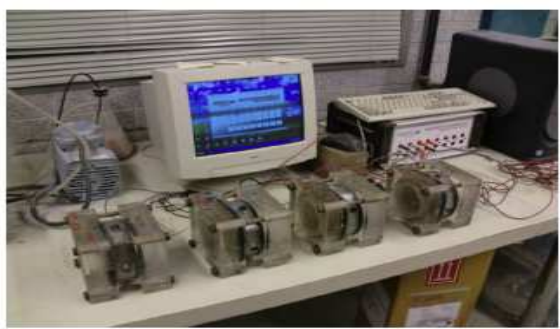

Figure 10. Rapid chloride permeability test setup

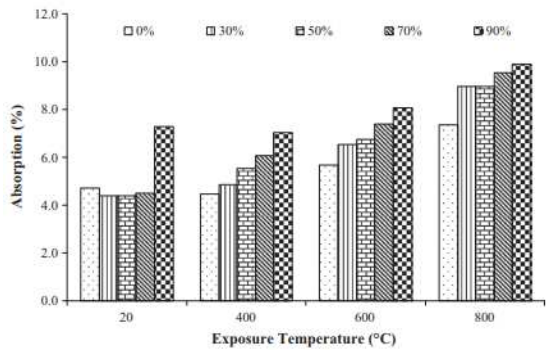

Figure 11. The absorption of concrete including high-volume fly ash after exposure to temperature

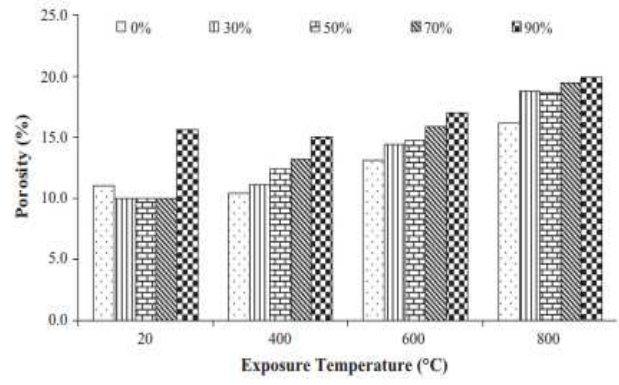

Figure 12 . The porosity results of concrete including highvolume fly ash after exposure to temperature

2.4.4. Rapid chloride permeability results: Figure 13 shows the results for the rapid chloride permeability test (RCPT) of the concretes incorporating high-volume FA exposed to 400, 600 and $800^{\circ} \mathrm{c}$ temperature. Concrete containing $90 \% \mathrm{FA}$ had the highest level of RCPT at all temperatures and the lowest levels of RCPT were obtained for concrete containing 30\% FA in comparison to other FA concretes at all temperatures. As it is shown in the test results, RCPT results increased as the test temperature was increased.

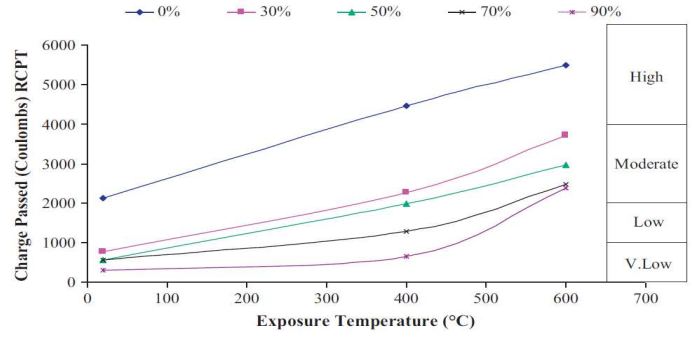

Figure 13. RCPT results of concrete including high-volume fly ash after exposure to temperature

2.4.5. Compressive strength: Figure 14 indicates the results for the compressive strength of the concretes incorporating FA exposed to high temperature. The lowest value of compressive strength belonged to the concretes containing $90 \% \mathrm{FA}$ at $400^{\circ} \mathrm{C}$, $600^{\circ} \mathrm{c}$ and $800^{\mathrm{a}} \mathrm{c}$. The results showed that the compressive strength of concretes increased remarkably as the temperature exceeded $400^{\circ} \mathrm{c}$. The observed loss of strength at increasing temperatures may be related to loss of bound water, increased porosity and consequently, increased permeability which makes the concrete progressively more susceptible to further destruction (Rashad 2015; Zabihi-Samani and Ghanooni-Bagha 2018b).

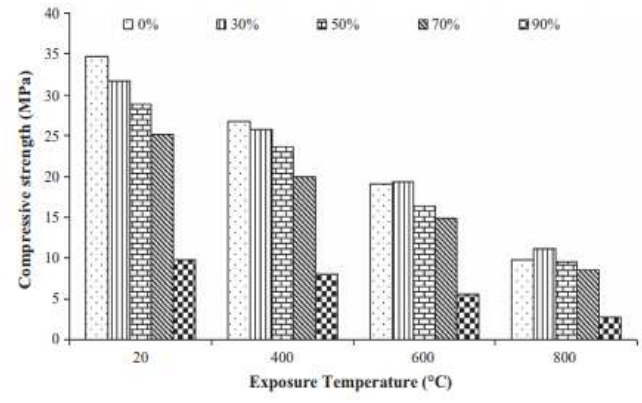

Figure 14. Compressive strength of concrete including fly ash after exposed to temperature

\section{CONCLUSION}

1. Production of concrete incorporating CFA with high fracture toughness is possible.

2. Under the condition of commissioning the concrete after 28 days, the preferred solution is to use composites containing $20 \%$ CFA additive.

3. The UCS showed that RCA+15\% FA was found to be the optimum blend from a strength development perspective at both room temperature and $40^{\circ} \mathrm{c}$ temperature.

4. Outcomes of the fracture toughness and the compressive strength are convergent qualitatively in concretes containing FA.

5. Fracture toughness and compressive strength of FA-30 concrete is higher compared to the results achieved from control concrete, after 180 and 365 days.

6. Increase in high temperature up to $800^{\circ} \mathrm{c}$ ends in a significant increase in absorption value for both FA and reference concrete. 
7. The lowest amount of porosity belonged to the concretes incorporating $30 \% \mathrm{FA}$.

8. By increasing the FA content, value of RCPT considerably reduces up to $70 \%$ replacement, however, the RCPT values obtained from $90 \%$ FA replacement significantly increased and becomes the highest compared to all concretes.

\section{References}

Amini F, Zabihi-Samani M (2014) A Wavelet-Based Adaptive Pole Assignment Method for Structural Control ComputerAided Civil and Infrastructure Engineering 29:464-477 doi:10.1111/mice.12072.

Arulrajah A, Mohammadinia A, Horpibulsuk S, Samingthong W (2016) Influence of class F fly ash and curing temperature on strength development of fly ash-recycled concrete aggregate blends Construction and Building Materials 127:743-750 doi: https://doi.org/10.1016/j.conbuildmat.2016.10.049.

Blissett RS, Rowson NA (2012) A review of the multicomponent utilisation of coal fly ash Fuel 97:1-23 doi: https://doi.org/10.1016/j.fuel.2012.03.024.

Brandt AM (1990) Cement-based Composites: Materials, Mechanical Properties and Performance. CRC Press,.

Ghanooni-Bagha M, Shayanfar M, Reza-Zadeh O, ZabihiSamani M (2017) The effect of materials on the reliability of reinforced concrete beams in normal and intense corrosions Eksploatacja i Niezawodnosc - Maintenance and Reliability 19:393-402 doi:10.17531/ein.2017.3.10.

Golewski GL (2017) Improvement of fracture toughness of green concrete as a result of addition of coal fly ash. Characterization of fly ash microstructure Materials Characterization 134:335-346 doi: https://doi.org/10.1016/j.matchar.2017.11.008.

Golewski GL (2018) Green concrete composite incorporating fly ash with high strength and fracture toughness Journal of Cleaner Production 172:218-226 doi: https://doi.org/10.1016/j.jclepro.2017.10.065.

Golewski GL, Sadowski T (2012) Experimental Investigation and Numerical Modeling Fracture Processes under Mode II in Concrete Composites Containing Fly-Ash Additive at early Age Solid State Phenomena 188:158-163 doi: 10.4028/www.scientific.net/SSP.188.158.

Hemalatha T, Ramaswamy A (2017) A review on fly ash characteristics - Towards promoting high volume utilization in developing sustainable concrete Journal of Cleaner Production 147:546-559 doi: https://doi.org/10.1016/j.jclepro.2017.01.114.

Jayapalan AR, Lee BY, Kurtis KE (2013) Can nanotechnology be 'green'? Comparing efficacy of nano and microparticles in cementitious materials Cement and Concrete Composites 36:1624 doi: https://doi.org/10.1016/j.cemconcomp.2012.11.002.

Karahan O (2017) Transport properties of high volume fly ash or slag concrete exposed to high temperature Construction and
Building Materials 152:898-906 doi: https://doi.org/10.1016/j.conbuildmat.2017.07.051.

Kosmatka S, Kerkhoff B, C. Panarese W (2002) Design and Control of Concrete Mixtures.

Mehta PK (2002) Greening of the concrete industry for sustainable development vol 24

Mo KH, Johnson Alengaram U, Jumaat MZ, Yap SP (2015) Feasibility study of high volume slag as cement replacement for sustainable structural lightweight oil palm shell concrete Journal of Cleaner Production 91:297-304 doi: https://doi.org/10.1016/j.jclepro.2014.12.021.

Rashad AM (2015) Potential use of phosphogypsum in alkaliactivated fly ash under the effects of elevated temperatures and thermal shock cycles Journal of Cleaner Production 87:717-725 doi: https://doi.org/10.1016/j.jclepro.2014.09.080.

Zabihi-Samani M, Amini F (2015) A cuckoo search controller for seismic control of a benchmark tall building Journal of Vibroengineering 17:1382-1400.

Zabihi-Samani M, Ghanooni-Bagha M (2018a) An optimal cuckoo search-Fuzzy logic controller for optimal structural control International Journal of Optimization in Civil Engineering 8:117-135.

Zabihi-Samani M, Ghanooni-Bagha M (2018b) Optimal Semiactive Structural Control with a Wavelet-Based Cuckoo-Search Fuzzy Logic Controller Iranian Journal of Science and Technology, Transactions of Civil Engineering doi: 10.1007/s40996-018-0206-0.

Zabihi-Samani M, Shayanfar M, Safiey A, Najari A (2018) Simulation of the Behavior of Corrosion Damaged Reinforced Concrete Beams with/without CFRP Retrofit Civil Engineering Journal 4:958-970 doi: 10.28991/cej-0309148. 